\title{
Los verdaderos héroes
}

\section{True heros}

\author{
Eugenio Matijasevic • Bogotá, D.C. (Colombia)
}

A mediados de la década de 1960 se emitió, a través de los canales de la televisión estadounidense afiliados a la cadena NBC, Star Trek, una serie de ciencia ficción cuyos índices de audiencia televisiva (aquí estaría bien empleado el barbarismo rating) no fueron los esperados, por lo que la serie se canceló al finalizar su tercera temporada. La versión para América Latina, doblada en México, se llamó Viaje a las Estrellas y se transmitió en Colombia entre 1967 y 1970, con un año de retraso con respecto a la versión original (1).

Con el paso del tiempo, por alguno de esos conjuntos de razones ininteligibles que exasperan a los deterministas, la fracasada serie se fue convirtiendo lentamente en un fenómeno de culto y, tímidamente al comienzo, los productores se atrevieron a hacer una serie de dibujos animados diez años después de La Serie Original (como denominan los fanáticos de Star Trek, autodenominados trekkers, $a$ las tres temporadas iniciales) e incluso una película catorce años después. Aupados en la multiplicación exponencial de los medios de comunicación de las últimas décadas y sobre todo en el desarrollo de la internet, los trekkers se hicieron cada vez más numerosos, circunstancia que no pasó desapercibida para los productores, que inundaron el mercado con todos los artilugios imaginables capaces de extraer hasta la más ínfima partícula de ese filón de oro. La franquicia de Star Trek comprende en la actualidad cinco series de televisión (la mencionada Serie Original, La Próxima Generación, Espacio Profundo Nueve, Voyager y Enterprise), una serie animada, once películas, más de doscientas novelas (libros de bolsillo), catorce series de historietas, innumerables juegos (de vídeo, de consola, en línea, de tablero, de cartas, de roles) y hasta convenciones de trekkers en los lugares más disparatados de la tierra (desde Vulcan-Alberta-a Pocono Manor-Pensilvania-, pasando por Londres, Nashville, Atlanta y, cómo podía faltar, Las Vegas en donde tiene lugar anualmente la Official Star Trek Convention), sin contar toda la parafernalia que acompaña a este tipo de empeños mercantiles: gorras, camisetas, toallas, relojes, llaveros, pocillos, uniformes, muebles (!la silla del capitán en el puente de mandoi) y cuanto objeto sea susceptible de portar uno de los iconos de la franquicia (2).

Patterns of Force, el quincuagésimo episodio de la serie original deViaje a las Estrellas (según el orden de difusión, no el de producción), vigésimo primero de la segunda temporada, escrito por John Meredyth Lucas y dirigido por Vincent McEveety (3), se llamó en castellano Por Medio de la Fuerza y comienza, como todos los de la serie original para Latinoamérica, con una imagen de la nave Enterprise surcando rauda el espacio interestelar mientras una voz en off declama: "Estos son los viajes de la nave espacial Enterprise. Su misión durante cinco años: explorar nuevos y extraños mundos, descubrir otros sistemas de vida y nuevas civilizaciones, llegando hasta donde jamás antes llegó el ser humano" (4). En este episodio la acción se desarrolla en la "fecha estelar" (stardate) 2534.0, correspondiente aproximadamente al 14 de Julio de 2325 EC de acuerdo con el Star Trek Stardate calculator (5). La tripulación de la nave Enterprise ha sido comisionada para buscar en el planeta Ekos al profesor John Gill, un historiador dedicado en el momento en que se desarrolla la trama a una especie de antropología del siglo XXIV, en el curso de cuyo trabajo de campo ha desaparecido sin dejar rastro. Antaño el profesor Gill había sido docente del capitán Kirk (el comandante de la nave) en la Academia de la Flota Estelar, y ha sido además un escritor prolífico, en cuyos libros aprendió el señor Spock (director científico -science officer-de la Enterprise, de padre vulcaniano y de madre terrícola) los avatares de la historia humana: "lo que más me impresionó fue su enfoque de la historia terrícola a partir de causas y motivaciones en lugar de fechas y
Dr. Eugenio Matijasevic: Editor General, Acta Médica Colombiana. Bogotá, D.C. (Colombia).

E-mail: eugenio.matijasevic@gmail.com Recibido: 04/VII/2012 Aceptado: 05/VII/2012 
eventos", le confiesa Spock a Kirk. Teletransportados a la superficie del planeta, el capitán Kirk y el señor Spock se dan cuenta de que los habitantes de Ekos, antaño un pueblo pacífico, han transformado su sociedad en un régimen nazi en el que el profesor Gill ostenta el título de führer. Luego de numerosas peripecias, inicialmente como prisioneros de los nazis y luego como fugitivos apoyados por la resistencia, Kirk y Spock se las ingenian para poner la casa en orden. De regreso a la nave, Spock le dice al capitán: "Nunca entenderé a los seres humanos, ¿Cómo pudo un hombre tan brillante, una mente tan lógica como la del Profesor Gill, cometer un error tan fatal?". "Gill extrajo la conclusión errada de la historia -le responde el capitán-, el problema con los nazis no era simplemente que sus líderes fueran malvados psicópatas, lo eran, pero el principal problema, creo, era el Principio del Líder". Spock hace un gesto que el Dr. McKoy, director médico a bordo, interpreta como una solicitud de aclaración y trata de explicarle a qué Principio (de la psicología o de la sociología del futuro) se refiere el Capitán Kirk: "Lo que él trata de decir, Spock, es que un hombre que alcanza demasiado poder [...] no puede resistir la tentación de jugar a Dios". "Gracias, Doctor, -le interrumpe Spock- soy capaz de captar el significado". "Lo cual también prueba-continua McCoy-otro proverbio terrícola: 'el poder absoluto corrompe absolutamente'; inteligentes estos terrícolas, ¿No le parece, Spock?". "Sí -le responde Spock-, terrícolas como Ramsés, Alejandro, César, Napoleón, Hitler, Lee Kuan... Toda la historia de su Tierra está hecha a base de hombres persiguiendo el poder absoluto" (6).

Sabemos bien poco del Lee Kuan de Viaje a las Estrellas, a quien no se debe confundir con Lee Kuan Yew, el personaje histórico, padre de la patria de la República de Singapur, pero por lo referido en este episodio de Viaje a las Estrellas es el nombre de alguien que trató de dominar la Tierra mucho antes de las aventuras del capitán Kirk y el señor Spock, en algún momento entre el siglo XXI y el siglo XXIII.

Tampoco sabremos mucho más sobre Lee Kuan cuando vuelva a ser mencionado en el décimo cuarto episodio de la tercera y última temporada de la serie original, el episodio 69 (71 en orden de producción): A quien destruyen los dioses (Whom gods destroy por su título original en inglés), escrito por Lee Erwin y Jerry Sohl y dirigido por Herb Wallerstein (7). El título del episodio se refiere al aforismo: "A quien los dioses quieren destruir, antes lo enloquecen". Esta frase, que todo el mundo cita y que se atribuye, quizás erróneamente, a Eurípides, en realidad no existe ni existió nunca en griego clásico, existe sólo en latín: Deus quos vult perdere, dementat prius, aunque otros la citan como Quem deus vult perdere, prius dementant. Los entendidos consideran que se trata de un pasaje alterado de una obra perdida de Eurípides y que la frase surgió del índice elaborado por Joshua Barnes en 1694 para la edición de la Universidad de Cambridge de las Obras de Eurípides. En este texto, entre los fragmentos inciertos de Eurípides, se cita una frase atribuida a éste por Atenágoras, frase que tiene en griego un sentido similar aunque no tan rotundo como el latinajo que creó Barnes para el índice. La frase griega en cuestión dice, palabras más palabras menos, que siempre que una divinidad prepara un mal para un hombre primero le extravía o le daña la voluntad o la capacidad de deliberación. La sentencia que hizo época no es pues una cita de Eurípides o su traducción al latín sino el "resumen" en latín que, de una frase que Atenágoras atribuyó a Eurípides, hizo Barnes para el índice temático del libro (8). Richard Dodds asegura que ni en Homero ni en Hesíodo se encuentra una exposición de tal doctrina a pesar de que Licurgo la atribuye a "ciertos poetas antiguos", a los que no nombra: "Cuando la cólera de los $\delta \alpha \iota \mu \mathrm{ov}$-daimon, dioses menores que rigen el destino individual de cada persona- quiere hacer daño a un hombre, lo primero que hace es quitar de su mente el buen entendimiento y entregarle al peor juicio, de modo que no puede darse cuenta de sus propios errores" (9). En A quien los dioses destruyen, la mención de Lee Kuan no ocurre en boca de ninguno de los tripulantes de la nave Enterprise, sino del malvado Garth, antiguo Capitán Interestelar de una nave hermana de aquella, actualmente confinado en el planeta Elba II, una colonia penitenciaria para criminales psicópatas. La Enterprise llega a Elba II, cuyo nombre es una clara alusión del libretista a la Elba terrestre, destino final de un líder del pasado, transportando un suero que, administrado a los prisioneros, conseguirá curarlos de su insania. Teletransportados a Elba II en la fecha estelar 5718.3 (correspondiente aproximadamente al 19 de septiembre de 2328 EC), el Capitán Kirk y el Señor Spock pronto se dan cuenta de que la colonia penitenciaria está ahora bajo el control de los prisioneros y que éstos, dirigidos por Garth, han desarrollado la capacidad de transformar a voluntad su apariencia. Garth, con un cuerpo y unas facciones en todo similares a los del capitán Kirk y travestido como éste, intenta ser teletransportado a la nave Enterprise para tomar el control de la nave y continuar su carrera ya no como amo de Elba II sino como amo del universo. El capitán Kirk es hecho prisionero por Garth, ahora bajo la apariencia de Kirk, y en un diálogo lleno de imaginación, en el que un Kirk verdadero habla con un falso Kirk sin que los espectadores sepan al principio quién es quién, Kirk trata de retrotraer al otro Kirk a la época en que eran condiscípulos en la Academia de la Flota Estelar e intenta hacerle recordar su brillante pasado como Capitán Interestelar, momento en el que Garth se descubre al responder: "yo soy Lord Garth, Amo del Universo, usted duda de mí sólo porque aún no he sido coronado". "No, señor -trata de argumentarle el verdadero Kirk-, escúcheme, yo...”. “Deténgase!, de rodillas” y ante la negativa de Kirk, Garth enfurece: "¡De rodillas ante mí!, todos aquellos que me antecedieron fracasaron. ¡Alejandro, César, Napoleón, Hitler, Lee Kuan, Krotus! ¡Todos ellos son polvo! ¡Pero yo triunfaré! ¡Yo llevaré a cabo la última conquista!" (10).

De Krotus nada sabemos, es la única vez que se menciona en la serie original. El final del episodio no importa (obviamente triunfa Kirk, en este caso gracias a un juicio Salomónico de Spock), pero -y esto es lo importante- para la mayoría de 
los televidentes de entonces resultaba inadmisible mezclar en una misma categoría, como en los dos episodios mencionados, a Hitler con Alejandro Magno, con Julio César y con Napoleón. Según Garth, todos pertenecían a la misma categoría de fracasados: poderosos anhelantes de más poder que fallaron en su intento de convertirse en amos del mundo conocido. Según Spock todos pertenecían a la misma categoría de los terrícolas: los personajes en cuestión eran sólo el epítome de una especie que habitaba la tierra, especie para la cual la contribución de cada individuo al desarrollo de la historia no era otra cosa que luchar de manera absurda e inicua por alcanzar más y más poder sobre otros individuos de su propia especie. Pero, cualquiera que fuese la categoría -la de Spock o la de Garth- en la que Hitler, Napoleón, Julio César y Alejandro terminaban siendo de la misma ralea, lo que quedaba en claro -y aquí aparece la intención de los libretistas-era que estos personajes, todos, al pertenecer a tales categorías, no podían pertenecer a la categoría de héroes en la que algunos figuraban en los libros de historia sino que, más bien, quedaban todos confinados a la categoría de megalómanos sociópatas tiránicos en la que figuraban en los libros de historia solo algunos de ellos.

El dictamen de Viaje a las Estrellas con respecto a esos personajes que las últimas generaciones ya no mirarán como héroes es, pues, implacable y demoledor. Nadie se salva. Y no se trata de que se haya retomado el antiguo parámetro bíblico para decir que son ídolos con pies de barro, semidioses que tenían demasiados aspectos humanos que los hacían falibles pero cuyas falencias podían ser pasadas por alto ante la estatura de su heroísmo, es más sencillo: no son héroes, son cualquier otra cosa menos héroes. Se argüirá que los libretistas y directores de una serie de televisión que apenas tuvo impacto en su momento tuvieran el criterio para definir por el resto de nosotros quienes son héroes o no. Al fin de cuentas se trata de lo que entonces llamábamos un simple "enlatado" cargado de ideología imperialista y no de un análisis crítico serio basado en las premisas de una determinada filosofía política o de una investigación sociológica fundada en la academia. Pero una argumentación tal errará en el punto en el que quiero hacer énfasis. No es que los libretistas de Viaje a las Estrellas pudieran escapar a la ideología dominante y realizaran unos análisis histórico-políticos vedados al resto de los mortales. También ellos estaban inmersos en el debate ideológico de entonces, también ellos experimentaron presiones por parte de productores y seguramente también de políticos para que las cosas se dijeran de una determinada manera y no de otra, pero expresaron ciertas preferencias, fruto del debate ideológicopolítico de la época y lo hicieron con el suficiente acierto para que muchas personas se identificaran con sus propuestas. Era cuestión de elección, otras series televisivas "enlatadas" de la época (Combate, Bonanza, Mr. Solo, El Santo) también tomaron posición en el debate de la época, sólo que en plena guerra fría tomaron partido a favor de la corriente (como seguramente lo hicieron las series televisivas soviéticas que no vimos pero que se vieron en los países detrás de la cortina de hierro) mientras que algunas series, como la de este ejemplo, aunque estaban alineadas (¿quién podría no haberlo estado en ese entonces?) optaron en muchos casos por una tercera vía, la del humanismo. Con respecto a un material tan sensible en la época como la política exterior de los Estados Unidos de América, ejemplificada de muy diversas maneras en la trama de Viaje a las Estrellas, en la serie casi siempre se adoptó una política antiguerrerista y de no intervención (11). Pero bueno, de esa época mítica de Viaje a las Estrellas no queda ahora nada. La victoria ha sido de los comerciantes.

Esta manera de acercarse a Alejandro, Julio César y a otros "héroes" por el estilo, no es nada nueva. Cuando Mario Bunge se pregunta por la razón para llamar Grande a Alejandro el Grande (o Magno, como se prefiera) su pregunta trae implícita la respuesta: "¿A Alejandro de Macedonia se le llama el Grande a pesar de haber cometido innumerables crímenes de guerra o porque los perpetró a una escala gigantesca e impunemente?" (12).

Y no es que Bunge soslaye que el paso del tiempo y los cambios culturales acaecidos den pié a la posibilidad de que un "héroe" de ese entonces pudiera ser mirado hoy como un criminal de guerra. Tabién entonces hubo muchas personas que los vieron así. El ejemplo preciso es otro de los fracasados nombrados por Garth: Julio César. Para muchos de sus contemporáneos (Pompeyo, Cicerón, Catón, por nombrar sólo unos cuantos) Julio César fue un delincuente apátrida, traidor a la república (¿cuál, si no, fue la causa de las guerras civiles?) y un criminal de guerra. Exactamente esto último fue lo que afirmó Catón en el senado cuando lo acusó de haber masacrado más allá del Rin -el límite natural entre la Galia y Germania- a 300.000 habitantes de las tribus germanas de los Usipos y los Téncteros a pesar de haberles dado su palabra de que los protegería (13): "Julio César debería ser entregado a quienes venció -solicitó Catón- para que así la maldición por haber roto la palabra empeñada caiga sobre su cabeza". El Senado, sin embargo, profusamente sobornado, no sólo no lo entregó a los germanos sino que decretó sacrificios a los dioses y festividades con suspensión de todos los asuntos de negocios durante 15 días, cosa antes nunca vista (14). Muchos consideran inválido el testimonio de Catón por tratarse de uno de los principales enemigos políticos de Julio César, pero los escritos de sus amigos políticos y los del propio Julio César, no dejan lugar a dudas: se trataba de un criminal de guerra que, aunque evaluar los hechos de entonces a la luz del derecho humanitario actual resulte un anacronismo, no hubiera salido indemne de un tribunal como el de La Haya. Entre muchos posibles, un sólo ejemplo narrado por el propio Julio César, tomado de sus Comentarios sobre la Guerra de las Galias, me dará la razón: cuando Vercingetórix se hizo fuerte en Alesia, Julio César puso sitio a la ciudad y construyó a su alrededor 17 kilómetros de fortificaciones que la cercaban por completo atrapando en su interior a la población civil de Alesia junto con los 80.000 guerreros galos que se habían refugiado en ella. Otros guerreros galos, de tribus vecinas a Alesia, atacaron a Julio César por los flancos y éste construyó otro círculo de 
fortificaciones alrededor del inicial, de tal manera que los sitiadores quedaban a su vez sitiados aunque con acceso al agua y a campos de trigo a los que no tenían acceso los habitantes de Alesia. Cuando el hambre de los sitiados se hizo insoportable los guerreros de Vercingetórix, intentando evitar una masacre, dejaron salir de la ciudad a las mujeres y a los niños, pero estos quedaron atrapados entre las dos líneas de defensa construidas por los romanos. El propio Julio César relata que "llegándose hasta las fortificaciones romanas les suplicaron que los recibieran como esclavos y les dieran de comer, pero César [Julio César siempre se refiere a si mismo en tercera persona], poniendo guardias en la estacada, prohibió que fueran recibidos" (15). Murieron de inanición entre las líneas romanas en el año 52 AEC, antes de la derrota definitiva de Vercingetórix y de la caída de las Galias.

Según Plinio el viejo, Julio César "peleó en 50 batallas con las banderas desplegadas [y,] sin contar sus victorias en las Guerras Civiles, dio muerte a 1.192.000 de sus enemigos; por mi parte, sin embargo, no le concedo por ello especial gloria, considerando el gran daño que le infligió a la humanidad, lo cual, de hecho, él mismo reconoció al omitir registrar los asesinatos ocurridos durante las Guerras Civiles" (16).

Pero Julio César no estaba solo en esto, todo el "heroico" estado Romano estaba concebido como una máquina de expoliación de los productos y riquezas de otros pueblos a los que subyugaba o exterminaba si no aceptaban tratos ignominiosos. En tiempos de Vespasiano, las legiones romanas al mando de Julio Agrícola invadieron Britania dispuestas esta vez a dominar por completo su territorio y subyugar a sus indómitos habitantes. Llegaron en el verano del año 77 EC y con su empeño habitual y el aparato de guerra del que siempre hicieron gala, fueron dominando una a una las tribus de lo que hoy es Inglaterra. En los límites con Escocia, sin embargo, una tribu se resistía, la de los pictos, también llamados caledonios por ser descendientes de estos. Durante años los campesinos caledonios lograron evitar un enfrentamiento directo con los ejércitos romanos, pero al final del verano del 83 Agrícola tomó por asalto los graneros caledonios, repletos de grano inmediatamente después de la cosecha. Ante la disyuntiva entre pelear o morir de inanición durante el invierno, los caledonios, al mando de Calgaco, organizaron a toda prisa un ejército. Treinta mil campesinos pictos mal armados y mal entrenados se enfrentaron a 20.000 legionarios del ejército profesional más poderoso de la tierra (algunos hablan de 30.000 legionarios) en la batalla del Monte Graupius. Acompañando a Agrícola en Britania se encontraba Tácito, su yerno. En la biografía que éste escribió de su suegro transcribe una arenga de Calgaco a sus hombres antes de la batalla, en la que se refiere a los romanos como los "depredadores del mundo". Corrían ya tiempos de Domiciano. Muchos dudan de la autenticidad de esa arenga, pero bien sea que Calgaco la haya dicho y Tácito la haya transcrito o que Tácito la haya inventado y la haya puesto en boca de Calgaco como una especie de alegato en contra de Domiciano, su fuerza sigue intacta con el paso de los siglos como una de las más acabadas alabanzas en pro de la autodeterminación de los pueblos y en contra de las prácticas del imperio: "Cuando -concluye Calgaco- ya lo han devastado todo y les falta tierra [los romanos] escrutan el mar; codiciosos si el enemigo es rico y despóticos si es pobre, no se han saciado ni con oriente ni con occidente [...]; al robo, a la masacre y al rapto los denominan embusteramente gobierno; y donde crean un desierto lo llaman paz" (17). Cualquier similitud con otros imperios de la historia, incluso más recientes, no es pura coincidencia. Sobra decir que el Imperio venció en Monte Graupius: después de los primeros embates los campesinos-soldados de Calgaco se desorganizaron ante la coordinada presión de la máquina militar romana y algunos intentaron correr a refugiarse en los bosques vecinos pero fueron cerrados por la caballería romana. Cercados en el campo de batalla muchos se rindieron pero los romanos no se podían dar el lujo de tomar prisioneros y comenzó la matanza. "Al llegar la noche y con los soldados romanos cansados de matar”, refiere Tácito, terminó la masacre con sólo 360 bajas romanas contra 10.000 vidas de pictos.

Mucho se ha escrito sobre la empresa criminal de Napoleón Bonaparte, incluso desde el más recalcitrante análisis político de derecha (18), pero aún quienes lo ven como un criminal a gran escala terminan por admitir al menos que era un genio en el arte de la guerra. En estos meses se cumplen 200 años de la invasión Napoleónica a Rusia que prueba todo lo contrario: carente de estrategia y de táctica cruzó el río Niemen, el límite entre Polonia y Rusia, el 24 de Junio de 1812 con 420.000 hombres de su Grande Armée (otros calculan esa cifra en más de 600.000), llegó hasta Moscú el 14 de septiembre de 1812 con sólo 100.000 hombres. La ciudad había sido abandonada, el gobernador Feodor Rostopchin había ordenado retirar todas las provisiones, los pocos habitantes que quedaban se habían dedicado al pillaje de los pocos avituallamientos restantes y no habían dejado prácticamente nada. Esa misma noche comenzó el incendio de Moscú, provocado al parecer por saboteadores rusos que no querían que su ciudad cayera en manos francesas; cuatro quintas partes de la ciudad quedaron destruidas hasta los cimientos. Sin posibilidad de alimento y refugio en la ciudad abandonada Bonaparte tuvo que iniciar el regreso a París a mediados de octubre de 1812. A comienzos de noviembre Bonaparte se enteró del intento de golpe de estado por parte de su general Claude de Malet y regresó a París rápidamente para conjurar la traición, dejando lo que quedaba de su Grande Armée en manos del Mariscal Joachim Murat, pero este desertó para tratar de salvar su Reino de Nápoles y dejó al ejército en manos del hijastro de Bonaparte, Eugene de Beauharnais, quien cruzó de nuevo el río Niemen, esta vez en dirección a París, el 14 de diciembre de 1812 al mando de un ejército de 10.000 desarrapados (otros autores hablan de 22.000) que a duras penas lograron llegar a París con las manos vacías (19). Es ya clásica la Carte Figurative de Charles Joseph Minard que despliega sobre el mapa de Rusia el avance y retroceso de las tropas francesas al tiempo que muestra de manera proporcional el tamaño decreciente de las tropas, las fechas, la dirección en que viajaban y la 
temperatura (20) [Edward Tufte, padre de la teoría de visualización de datos, considera éste el mejor gráfico estadístico de todos los tiempos (21)].

Otros defienden al Napoleón que reorganizó a Europa y llevó los postulados humanistas de la Revolución Francesa hasta los más apartados rincones de Europa y del Imperio. La mayoría de esas alabanzas carecen de fundamento. La verdad monda y lironda es que la Revolución había echado abajo los privilegios de los aristócratas y Napoleón volvió a dejarlos en su sitio sólo que con una aristocracia remozada con la ascensión de sus familiares, sus amigos políticos y la cúspide de sus militares. No sólo en lo que se refiere a la desigualdad regresó Bonaparte las cosas a antes de la Revolución y la Declaración de los Derechos del Hombre, también otros logros humanistas de la Revolución fueron conculcados por el corso. La libertad de prensa, la libertad de expresión, la libertad de los esclavos. Después de la Revolución, el pueblo Francés, representado en La Convención Nacional había primero declarado la igualdad de derechos para los negros libres en 1792 y, luego, había emancipado a todos los esclavos, mucho antes que cualquiera otra nación, en 1794. En 1802, aprovechando un breve periodo de descanso en sus innumerables campañas de pillaje, Bonaparte envió a varios de sus generales a las colonias francesas del Caribe al mando de ejércitos bien equipados, con la clara instrucción de ocupar puestos clave, perseguir sin piedad a los rebeldes, desarmar a todos los negros, apresar a sus jefes y enviarlos a Francia para abrir el camino a la restauración de la esclavitud (22). A la mitad francesa de La Española, actual Haití, conocida entonces como Saint-Domingue, envió al General Leclerc, su cuñado, al mando de 25.000 soldados. En los meses siguientes morirían bajo las armas de Leclerc 150.000 personas y Toussaint-Loverture, jefe de los rebeldes, sería hecho prisionero y enviado a Francia en donde moriría encarcelado un año después (23).

"La historia la escriben los vencedores", parece que dijo Winston Churchill alguna vez y en algún lado, pero nadie ha podido encontrar nunca ni el momento ni el lugar exacto en el que él nos regaló esta frase y, aunque tiene las características de las frases lapidarias de Churchill, la frase no va más allá, excepto en el análisis, este no lapidario sino histórico-social, que de ella hace Howard Zinn, el historiador norteamericano: "en cada época existe una cara oculta (e indeseable) de la realidad a la que la historia casi nunca se refiere puesto que la historia se escribe a partir de los documentos y vestigios que dejan los privilegiados: sabemos de la política del pasado a través de los documentos que dejaron los políticos, sabemos de la economía del pasado gracias a los vestigios que dejaron los empresarios, sabemos de la esclavitud a partir de los registros que dejaron los dueños de las plantaciones y sabemos de la manera de pensar de una época a partir de los escritos que legaron sus élites intelectuales" (24). "Son los vencedores -continúa Zinn- quienes dan nombre a las batallas y son los satisfechos los que bautizan cada época de la historia, pero ¿qué significaron las Cruzadas para los millares de campesinos que murieron en ellas? ¿o el Renacimiento para la vasta mayoría que sufría mientras los Médicis financiaban las artes? ¿o la Ilustración para los no ilustrados? [...]”. Obviamente, si escarbamos con mucha paciencia, concluye Zinn, encontraremos una que otra traza dejada por quienes no escribieron la historia o, en ocasiones, alguien en el límite de su época o en las fronteras de su clase, con gran esfuerzo, logra salvar para nosotros lo que la historia ha querido enterrar. Parece obvio, por tanto, que los héroes que figuran en los libros de historia son los héroes que quienes han escrito la historia desean que consideremos como tales. Pero la mayoría de ellos no pasan la prueba de Spock: esos supuestos héroes no eran, como los héroes griegos (altruistas, virtuosos y justos), verdaderos héroes, eran seres humanos persiguiendo el poder, con la diferencia con respecto a sus contemporáneos de que alcanzaron en su región o en su tiempo algo muy parecido al poder absoluto y utilizaron ese mismo poder para hacerse inscribir en la historia como héroes.

La palabra héroe se deriva en la mayoría de las lenguas occidentales de la palabra griega $\eta \rho \varsigma-$-heros-, originalmente "defensor" "protector" (25), y no debe confundirse con e $\rho \circ$ (eros: deseo y, también, pero con mayúscula, el nombre propio del dios del amor). El nombre de héroes, de hecho, fue dado en la antigua Grecia a seres mitológicos mitad hombres y mitad dioses, casi siempre hijos de un dios y una mortal $\mathrm{o}$, en ocasiones, de una diosa y un mortal, cuyas hazañas altruistas los hacían dignos de veneración y de imitación. En todo caso no era el hecho de tener entre sus progenitores a un dios lo que los hacía héroes sino sus hechos, sus trabajos en este mundo ayudando a otros, defendiendo a los oprimidos y a los injustamente perseguidos, llevando a cabo acciones fuera de lo común en las que primaba el bien colectivo sobre la tranquilidad individual. En general a los héroes griegos nunca los vemos haciendo daño injustificado a otros excepto en circunstancias extrañas, víctimas de la confusión o de la locura impuestas por un dios. También hubo héroes o semidioses en otras culturas europeas, como la germana, la nórdica o la eslava, pero con el tiempo la denominación perdió su sentido original y pasó a designar a cualquier persona capaz de realizar acciones supuestamente sobrehumanas, no sólo en el sentido de la fuerza o la habilidad puestas en juego sino sobre todo en el sentido ético de que, en circunstancias excepcionales en las que alguien que no fuera un héroe hubiese elegido desistir o huir, el héroe llevó a cabo una acción en la que el bienestar de otros primó sobre el bienestar personal.

Resulta claro, entonces, que héroe y guerrero no son sinónimos y ni siquiera pertenecen a la misma categoría. Claro que hubo héroes guerreros como en las Termópilas, donde un puñado de hombres defendió la libertad de los griegos en contra de un poderosísimo ejército invasor. Pero esto nos lleva al tema de las guerras justas e injustas en el que desde Aristóteles a la ONU con su doctrina de Intervención Humanitaria, pasando por Cicerón, Agustin de Hipona, Tomás de Aquino, Hobbes y Kant todos parecen haber marrado el punto porque, querámoslo o no, las guerras siguen siendo injustas para quien las sufre (26). 
Cada cultura y cada época de la humanidad han tenido sus héroes, de hecho es posible afirmar que cada uno de nosotros tiene sus héroes personales. En esta época de fenómenos de masa globalizados, sin embargo, el "culto a los héroes" ha sido denostado como si se tratara de un arcaísmo innecesario y la verdad llana es que hay "héroes" que no merecen ningún culto, no merecen ser modelo para nadie. Pero, puesto que parece incontrovertible que los seres humanos tenemos la propensión, tanto individual como colectiva, a rendir culto a lo largo de nuestras vidas a una persona o varias, casi como si se tratara de dioses, como si fuese una religión entregada a la adoración de hombres deificados, con la diferencia de que a estos dioses menores no les pedimos nada, no pretendemos, como en las verdaderas religiones, que medien entre los poderes sobrenaturales y nuestras necesitadas existencias mortales, sino que los usamos como un modelo a seguir o como un modelo educativo para nuestros hijos o para nuestros educandos o incluso como insignia de un cierto grupo social, hemos dado en abandonar el culto a los héroes y lo hemos sustituido por el culto a la celebridad, a tal punto que los términos héroe y celebridad comienzan, por craso error, a confundirse.

También los seres humanos dedicados a la medicina tenemos, como todo grupo social, unos héroes que consideramos propios y que, al mismo tiempo, desearíamos que fueran héroes para toda la humanidad. Estos héroes nuestros no fueron ni líderes de naciones, ni poderosos señores de la guerra, fueron médicos e investigadores y pacientes que no solo son dignos de alabanza sino modelos a imitar. La tecnificación de la medicina, con todas sus bondades, ha llevado sin embargo a que la enseñanza de la medicina haya adquirido cada vez más un sesgo tecnológico con un abandono creciente de las raíces humanísticas sobre las que los héroes de la medicina a los que me refiero (no voy a nombrarlos, cada quien en su fuero interno puede hacerlo) cimentaron las bases de nuestra práctica como una práctica profundamente humana.

Acta Médica Colombiana tiene a disposición de los lectores (y de los investigadores, historiadores, sociólogos, antropólogos y escritores) una sección que, desde antaño, se ha llamado Educación y Práctica de la Medicina. Dicha sección está abierta a la educación y a las humanidades en lo que tienen éstas que ver con nuestra profundamente humana actividad, la medicina, y quiero invitar a los potenciales autores a que, sin olvidar la investigación científica, dediquen parte de su actividad como investigadores a la indagación y búsqueda en el fructífero campo de las ciencias humanas (o humanidades, como prefieran llamarlas): en nuestra revista hay un espacio para la difusión de su pensamiento. En la presente edición, por ejemplo, Octavio Martínez nos ha regalado un artículo (27) paradigmático de lo que he venido diciendo: es posible ser muy buen investigador sin dejar de lado el aspecto humanístico, en este caso socio-histórico, de nuestra indagación médica.

A algunos les asusta la idea de una educación médica cimentada también en las humanidades, en la medida en que estas parecen no servir para nada puesto que no producen dividendos o no se manifiestan directamente en las estadísticas de atención en salud. Martha Nusbaum ha defendido recientemente la educación humanística con argumentos poderosos en un libro que precisamente se llama Not for Profit: why democracy needs the humanities (28).

\section{Referencias}

1. Amaral-Ceballos D (compilador). La televisión en Colombia, una historia para el futuro. Bogotá: Zona Ediciones; 2004: p 123.

2. Star Trek Official Store [Internet]. South Burlington, Vermont, Resolution Inc.; 2012 [citado el 25 de junio de 2012].Disponible en: http://store.startrek.com/

3. Star Trek Database [Internet]. New York, CBS Entertainment; 2012 [citado el 25 de junio de 2012]. Disponible en: http://www.startrek.com/database_article/patternsof-force

4. McDougall D, Oswald G, Hart H, et al. Star Trek The Original Series - Season 2 [Blue-Ray]. Shatner W, Nimoy L, DeForest K (actores). Color, NTSC. Idiomas: Inglés, Español, Francés. Región A/1. Paramount, Hollywood: septiembre 22, 2009.

5. Schmidt A. Calculate the Stardate of the Star Trek Future [Internet]. Andreas Schmidt; 2004 [citado el 25 de junio de 2012]. Disponible en:!http://www. hillschmidt.de/gbr/sternenzeit.htm

6. Chrissie's Transcripts Site [Internet]. The Star Trek Transcripts - Patterns Of Force. Easyspace; 2012 [citado el 25 de junio de 2012]. Disponible en: http://www.chakoteya.net/StarTrek/52.htm

7. McDougall D, Oswald G, Hart H, et al. Star Trek The Original Series - Season 3 [Blue-Ray]. Shatner W, Nimoy L, DeForest K (actores). Color, NTSC. Idiomas: Inglés, Español, Francés. Región A/1. Paramount, Hollywood: diciembre 15, 2009.

8. Padel R. Whom Gods Destroy: Elements of Greek and tragic madness. Princeton: Princeton University Press; 1995: 276 pp.

9. Dodds, Eric R. Los Griegos y lo Irracional. Madrid: Alianza Editorial; 1997: p. 49

10. Chrissie's Transcripts Site [Internet]. The Star Trek Transcripts - Whom Gods Destroy. Easyspace; 2012 [citado el 25 de junio de 2012]. Disponible en: http:// www.chakoteya.net/StarTrek/71.htm

11. Sarantakes NE. Cold War Pop Culture and the Image of U.S. Foreign Policy: The Perspective of the Original Star Trek Series. Journal of Cold War Studies 2005; 7 (4): 74-103.

12. Bunge M. Filosofía Política. Barcelona: Editorial Gedisa; 2009: p 490.

13. Plutarch. Lives, Volume VII, Demosthenes and Cicero, Alexander and Caesar. Caesar, 21, 1-3. Perrin B (Traductor). Cambridge Massachusetts: Loeb Classical Library; 1985: p 495.

14. Plutarch. Lives, Volume III, Pericles and Fabius Maximus, Nicias and Crassus. Comparison of Nicias and Crassus, 4, 3. Perrin B (Traductor). Cambridge Massachusetts: Loeb Classical Library; 1916: p 435.

15. Julio César. Guerra de las Galias. Libro VII, capítulo LXXVIII. García-Yebra V, Escolar-Sobrino H (traductores). Madrid: Editorial Gredos; 1996: p 220.

16. Pliny. Natural History 7, 25. In: Pliny's Natural history in thirty-seven books, Volume 1. Holland P (Traductor). Edimburgh: Printed for the Wernerian Club by G. Barclay: p 208. Consultado el 18/06/2011. Disponble en http://books.google. com/books?id=XrFgAAAAIAAJ\&printsec=frontcover\&source=gbs_ge_summar y_r\&cad $=0 \# v=$ snippet\&q=Julius $\% 20$ Caesar $\& \mathrm{f}=$ false

17. Tacitus. Agricola, Germania, Dialogue on Oratory. Hutton M, Peterson W (Traductores). Cambridge Massachusetts: Loeb Classical Library; 1914: pp 78-81.

18. Schroeder PW. Napoleon's Foreign Police: A Criminal Enterprise. The journal of Military History 1990; 54 (2): 147-162

19. Ségur PF, Conde D. La derrota de Napoleón en Rusia. Barcelona: Duomo Ediciones; 2010: 247 pp.

20. Friendly M. Visions and Re-visions of Charles Joseph Minard. Journal of Educational and Behavioral Statistics 2002; 27 (1): 31-51.

21. Tufte ER. The visual display of quantitative information. 2nd edition. Cheshire Connecticut: Graphic Press; 2001: p 207.

22. Hunt L. La Invención de los Derechos Humanos. Barcelona: Tusquets Editores; 2009: pp 182-186.

23. Girard PR. The Slaves Who Defeated Napoleon: Toussaint Louverture and the Haitian War of Independence, 1801-1804. Tuscaloosa: University Alabama Press; 2011: $456 \mathrm{pp}$

24. Zinn H. The Politics of History. Second edition. Chicago: University of Illinois Press; 1990: p 102

25. Harper D. Onlyne Ethymological Dictionary [Internet]. 2012 [citado el 25 de junio de 2012]. Disponible en: http://www.etymonline.com/index.php?search=hero

26. Bellamy AJ. Guerras Justas. México: Fondo de Cultura Económica; 2009: 412 pp.

27. Martínez O. La epidemiología en busca de contexto social. Acta Med Colomb 2012; 37(2): 93-96.

28. Nusbaum M. Not for Profit: why demcracy needs the humanities. Princeton: Princeton University Press; 2010: 192 pp. 